\title{
Temas municipalistas en el Consejo de Europa
}

Tiene en estos momentos gran actualidad la actividad diplomática de los diferentes Estados europeos, en orden a conseguir la unificación de criterios y actuaciones en materia económica, social, administrativa, etc., como premisa necesaria para, en su día, lograr la unidad política europea, que sirva de contrapeso. entre las dos grandes potencias que hoy ostentan la hegemonía en el Mundo. Manifestación de esta actividad son los tanteos y proyectos en orden al Mercado común, Euraton, etc., siendo nota característica dè ella, el que a diferencia de lo que sucedía con los tratados y alianzas de épocas pasadas, meros pactos entre Estados, pero conservando cada uno su soberanía, hoy la tendencia es a crear organismos supranacionales, soberanos y con personalidad propia, independiente de los Estados que son miembros de ellos; tal sucede con la Comunidad Europea del Carbón y el Acero (C. E. C. A.), cuyas decisiones son obligatorias para los Estados que la forman, y cuyos organismos no representan a los Gobiernos de Francia, Alemania occidental, Italia, Bélgica o Luxemburgo, sino a la comunidad formada por todos ellos.

Sin embargo, esta unificación con carácter supranacional y soberano, solamente se ha conseguido en la C. E. C. A. Las diferencias de religión, raza, idioma, nivel social, etc., representan graves obstáculos, sólo salvables con una firme decisión y un gran deseo de unidad, que hay que reconocer que tiene su origen en la actitud defensiva ante el peligro ruso. Por ello se ha dicho, con frase gráfica y exacta, que el miedo es el gran aglutinante de la comunidad europea. Cristalización de este deseo de unidad es el Consejo de Europa, que en su sede de Estrasburgo, realiza en sus distintos y múltiples organismos una fecunda labor que se proyecta a las más diversas actividades, $y$, entre ellas, las relaciones con la Adminis- 
tración local, a que vamos a referirnos por su interés en el campo municipalista.

Los días 12 y 14 de enero de 1957 , se celebró la primera Conferencia Europea de Autoridades locales, de la Asamblea Consultiva del Consejo de Europa, en la que se adoptaron acuerdos, en unos casos, y se emitieron dictámenes, en otros, sobre las materias siguientes: Crédito municipal, Aspectos locales de la Comunidad Europea de Carbón y el Acero, Participación de las Autoridades locales en la propaganda de la idea europea, Defensa y desarrollo de la Autonomía local.

Para no dar extensión excesiva a este trabajo, vamos a concretar nuestro estudio al tema de la autonomía local, que fué objeto de un informe de M. Dikson, en nombre de la Comisión de Asuntos Municipales y Regionales del Consejo de Europa, que previa discusión dió lugar al dictamen número 6, sobre Defensa y desarrollo de la Autonomía local, aprobado por la Conferencia por sesenta y dos votos a favor y dos abstenciones, en la sesión del 14 de enero de 1957.

Comienza su informe $\mathrm{M}$. Dikson diciendo que, en 11 de mayo de 1953, la 'Asamblea 'Consultiva del Consejo de Europa acordó $€$ mprender un estudio de los medios de asegurar la defensa y desarrollo de la autonomía local en los países miembros. Esta decisión obedeció a las consideraciones siguientes: A) La civilización europea y sus libertades fundamentales, tienen sus más sólidas y profundas raices én las franquicias locales; B) La contribución de las entidades locales es indispensable al buen funcionamiento del Estado democrático; C) Las autonomías locales son un freno, cada vez mayor, a las usurpaciones del Poder central.

Sienta a continuación la premisa de que el Municipio, al igual que la familia, es anterior al Estado, y la desarrolla diciendo que el Municipio constituye una comunidad natural que precede a la formación del Estado moderno, y deriva de la agrupación permanente de familias, tendente a la satisfacción de necesidades, que, cual las de seguridad y ayuda, no pueden realizar una familia sola.

Roger Collard escribía en el siglo pasado que (el Municipio, como la familia, son anteriores al Estado; la ley política los reconoce, pero no los crea). Es carácter esencial y primordial del Municipio li convivencia, pudiendo decirse que viene a ser la "familia politica». El Presidente Teodoro Heuss, ha dicho que los Municipios son más 
importantes que el Estado, y Napoleón esperaba que la prosperidad de Francia había de llegar de los Municipios.

Estudia M. Dikson la organización local en los distintos paises miembros del Consejo de Europa, distinguiendo dos grupos muy diferentes en atención a su estructura administrativa. El primer grupo comprende los Estados donde la administración es descentralizada, autónoma. El segundo, aquéllos en que es centralizada y autoritaria. Dice, muy gráficamente, que los Estados del primer grupo están organizados de la base a la cúspide (de bas en haut) y en el segundo sucede a la inversa.

Para determinar el grado de autonomía local en un pais basta considerar las relaciones existentes entre el Poder central y las Corporaciones locales. Hay autonomía cuando en las cuestiones concernientes a los intereses municipales o regionales, las Autoridades locales deciden libremente, según su propia apreciación, y con entera responsabilidad. Este sistema es practicado en Inglaterra, Holanda y Dinamarca; en la primera, como resultado de la evolución histórica de su régimen tradicional (self government); en la última por el contrario, como consecuencia de transformaciones radicales, no evolutivas, sufridas en determinados momentos de su historia. En el grupo de países de organización local centralizada, presenta la centralización carácter más acusado en Francia e Italia, y una forma más atenuada en Alemania y Austria. En los Estados de este segundo grupo, la centralización administrativa se deja sentir en todos los aspectos de la vida local. Así en Francia, para el abastecimiento de agua potable a una población de 200 vecinos, asunto de interés puramente local y sin repercusiones en la vida del Estado, es precisa la intervención del Poder central. De esta forma, y aun cuando en Derecho la iniciativa corresponda a las Autoridades locales, y el control haya de ser posterior al acto jurídico, en la práctica $y$ de hecho sucede a la inversa, puesto que tal acto es consecuencia de indicaciones y directrices del Poder central. Con el sistema de centralización los Municipios van perdiendo, poco a poco, su personalidad, para convertirse en meras subdivisiones administrativas. Los Alcaldes, al tener a su cargo numerosas funciones de carácter estatal, vienen a ser a la vez el primer Magistrado del Municipio y el último funcionario del Estado. Con gran claridad, y con observancias muy atinadas, se van exponiendo en el dictamen las condiciones esenciales para la existencia de una verdadera autonomía local, en la siguiente forma: 
1. Respeto de las libertades locales. - La descentralización requiere que las autoridades locales queden fuera de la jerarquía administrativa. Admitir oficialmente una línea de conducta, y no asegurar su aplicación efectiva, supone una falta de respeto y un fraude a la autonomía local. Es necesaria una reorganización administrativa, creando un clima favorable a la restauración y aplicación de esta autonomía.

2. Salvaguardia del carácter específico y apolítico de la vida local.-Las condiciones que se han de exigir a un Alcalde, son totalmente diferentes de las que debe reunir un Diputado, puesto que el primero representa al Ayuntamiento, en su conjunto, y no a las partes de población agrupadas según sus ideas políticas. La gestión de los intereses municipales nada tiene que ver con la dirección de los asuntos nacionales. Obsérvese como entre los españoles este principio no ha sido siempre aceptado. Basta recordar cómo en abril de 1931, unas elecciones municipales, supusieron, nada menos, que el cambio del régimen político de la Nación.

3. Definición de relaciones entre el Estado y el Municipio.- $\mathrm{El}$ Municipio es una entidad natural que ha de proveer a las necesidades de todos sus miembros. Es al mismo tiempo el marco geográfico en que se ejercitan las decisiones del Poder central. En lo que se refiere a los intereses propios de los habitantes de una entidad local, la autonomía debe de ser respetada, con desaparición de toda tutela administrativa ejercida por funcionarios del Estado. El control sobre los organismos locales se ha de referir únicamente al examen de la legalidad de sus actos jurídicos (la ley obliga en todo el territorio) y será ejercido por jurisdicción independiente del Poder central.

4. Autonomía de las finanzas locales.-La autonomía administrativa local está en razón directa de su autonomía financiera. En el dictamen número 1 de la Conferencia, aprobado en sesión de 14 de enero, sobre crédito municipal, del que fué ponente $M$. Janssens, se contienen muy atinadas observaciones sobre esta materia, que no podemos examinar por falta de espacio.

5. Fomento del espiritu municipal.-Considera esta cuestión de vital importancia, y estima que constituye una de las tareas que la Conferencia habría de realizar por sí misma, si dispusiese de medios suficientes.

Hace la interesante recomendación de que los maestros enseñen a los niños la importancia vital del iMunicipio. Verdaderamente, la 
indicación no puede ser más atinada. Si desde la escuela comienza el ciudadano a mirar al Municipio como cosa propia y a valorar debidamente su importancia, más adelante seguirá este interés y no se darán los casos de desvío hacia lo local, hoy por desgracia tan frecuentes.

La Conferencia, después de un largo debate, y a la vista de la diversidad de formas de Administración local en los Estados miembros del Consejo de Europa, diversidad derivada de la historia y las tradiciones de cada país, y que da lugar a concepciones diferentes, si no sobre el principio de autonomía propiamente dicho, sí sobre el detalle y medios para asegurarle, se limitó a trazar unas directrices de carácter general, contenidas en la declaración de principios que vamos a exponer sumariamente:

Los Municipios y las regiones constituyen el fundamento del Estado. Cada ciudadano consciente de sus obligaciones como miembro de la comunidad, debe contribuir al desenvolvimiento de unos y otras, participando activamente en la vida local.

Las verdaderas libertades municipales y regionales no pueden existir si los pueblos carecen de una firme voluntad de administrarse ellos mismos, y salvaguardar estas libertades oponiéndose a todo principio totalitario. Los ciudadanos, conscientes de su responsabilidad, deben obediencia a la ley, pero deben también, individual y colectivamente, rehusar someterse a todo poder arbitrario.

La aplicación de la ley ha de garantizar los derechos de las entidades locales y regionales, frente a las colectividades superiores.

Las libertades municipales y regionales deben estar defendidas por la Constitución de cada país, y garantizadas por un derecho de recurso ante jurisdicción independiente.

Los proyectos de ley reglamentando la organización general de las entidades locales, serán sometidos al informe previo de una representación de dichas entidades.

El ejercicio de toda función de interés local corresponde a las colectividades locales. Dentro del marco de la ley, ellas mismas determinarán por sí las normas de su ejercicio.

La Administración municipal o regional es responsable, en el ejercicio de sus funciones, ante la comunidad de los habitantes. Estos podrán, por las vías legales, exigir esta responsabilidad ante jurisdicciones competentes.

Sólo la conformidad con la ley de los actos de las entidades locales, estará sometida a control administrativo. Este control se 
ha de ejercer por organismos independientes. El control de oportunidad no se admitirá más que en los casos determinados en la ley. En estos juicios las Corporaciones locales podrán únicamente ser invitadas a reconsiderar sus decisiones.

Los recursos de las entidades locales se obtendrán de sus propias fuentes de ingresos. Si estas fuesen insuficientes, podrán completarse mediante cupos de compensación.

El poder de decisión en los asuntos locales, así como el acuerdo sobre medios financieros y su utilización, corresponde a los ciudadanos, mediante sus representantes. Del mismo modo, dentro del marco de las disposiciones legales, les corresponde el nombramiento, sueldos y mejoras de los funcionarios locales, así como la potestad disciplinaria sobre los mismos.

El territorio de un 'Municipio o región no podrá sar variado, sino por los trámites legales, y previa consulta de los habitantes afectados.

Los Municipios y las regiones tienen el derecho de adherirse a las organizaciones internacionales que admitan los principios que quedan enumerados.

Luis DE LA Riva y deL Hoyo Abogado y Secretario de r." categoría de Administración Local

\section{CRONICA \\ DE L \\ I CONGRESO IBEROAMERICANO DE MUNICIPIOS \\ SESIONES DE TRABAJO Y ACTOS SOCIALES \\ En este gran volumen, dirigido y editado por el Instituto de Estudios de Admi- nistración Local, están contenidas la relación de asistentes, las Ponencias pre- sentadas al Congreso, las Comunicaciones de los congresistas, los textos de las sesiones, los acuerdos y la descripción de los actos celebrados con motivo de tan magno acuntecimiento municipalista lberoamericano.}

Un volumen, en tela, de 1.010 páginas.

Precio: 300 pesetas

Pedidos a la

Sección de Publicaciones

DEL

Instrtuto de Estudios de Administración Local

J. Garcia Morato, 7 - Madrid 